\title{
Forecasting Insurance Sector Volatility In Amman Stock Exchange Using ARIMA Model ${ }^{*}$
}

\section{M. H. Alkhazaleh}

Faculty of Finance

And Business Administration

Department of Finance and Banking

\section{Hussein Ali Al-Zeaud}

Assistant Professor of Economics and Finance Department of Economic and Finance Administration Faculty of Finance and Business Administration Al-Albyt University

The Hashemite Kingdom of Jordan

\begin{abstract}
:
There are many forecasting techniques that can be used in the financial markets, the importance of forecasting is to able investment community to take their decisions about the future expectations, assets allocation, portfolio management, assets pricing and other benefits. This paper presents the Box-Jenkins model as one of the forecasting techniques, which we can use, in the financial time series. The main aim of this study is to predict volatility of Amman Stock Exchange as one of the emerging markets for the insurance sector. That is adopted to give an investment community a chance to plan about their buying or selling decisions for financial securities in the future. That is achieved by finding the tentative Autoregressive Integrated Moving Average (ARIMA) models that describe the equation of the forecasting sector.
\end{abstract}

The data are accumulated weekly from the web site of Amman Stock Exchange using the historical indices in the period from1/1/2005-1/4/2010.

We test the stationary by using unit root test which indicates that there is a stationary at level for insurance sector, and then use a minimum mean square error, $t$-statistics value and p-statistics value to choose the best ARIMA models at 95\% confidence interval. The resulted model for this study for insurance sector is:

$$
Z_{t}=\mu+\varphi_{1} Z_{t-1}+a_{t}
$$

From this proposed model we can get the forecasting equation for the insurance sector.

Volatility has turned out to be a subject matter of massive significance to almost anyone who is concerned in the financial markets, even as a spectator. In this paper, we present the advantage of ARIMA model in forecasting financial time series data. Amman stock exchange (Jordan) in particular insurance data was selected as a tool to show the ability of ARIMA model in forecasting financial time series, experimentally. Then, the weekly data was used to compute the values of volatilities in this study. Finally, the best ARIMA model was determined.

* This Research Was Submitted in January 2011, and Accepted for Publishing in April. 2012. 


\section{1- Introduction:}

Volatility is comparable with risk: high volatility is thought of as a sign of market distraction. Volatility as a noticeable fact as well as a thought remains fundamental to modern financial markets and academic research (Figlewski, 2004). In fact, extremely justified volatility can figure the basis for efficient price finding, while volatility dependence implies certainty, which is welcomed by traders and medium-term investors (Elena \& Storis, 2009). Forecasting volatility in financial markets is a very important information in hedging, asset pricing, asset allocation and portfolio management, because it is a technique to predict about events that maybe occur, and to determine the expected returns or losses in the future, hence investors take their decisions easily, and with no doubt. Also a high volatility of financial market requires well-organized power and risk management, in order to declare the competitiveness's and to well manage own funds (Hussein, 2007).

Juncal et al, (2006) studied the effect of changes in volatility dynamic behavior of emerging market Volatility. They investigated whether the dynamic behavior of stock market volatility in six emerging economies (Argentina, Brazil, Chile, Korea, Mexico, and Thailand). Paolo (2006) studied the analysis of financial crises for 156 stocks in 20 countries. He found the likelihood of these regime-shifts to be related to proxies for uncertainty among investors, exchange rate volatility, trade linkages, and liquidity. Zikovic (2007) studied Slovenia index (SBI-20), he used ARMA (Auto-Regressive Moving Average with) and GARCH.

Chien-Chiang et al. (2009) studied the stock prices and the efficient market hypothesis. The purpose of their study is to demonstrate whether different economic development levels exhibit the same efficient market hypothesis EMH. Alshiab (2006) studied the predictability of ASE Performance; he examined the univariate ARIMA forecasting model, using the ASE general daily index between 4/1/2004 and 10/8/2008. He found that the forecasting was not consistent with actual performance during the same period of the prediction over the coming 150 coming days. Al-Zoubi \& Al-Zoubi, (2007) studied the Market efficiency, time-varying volatility and the asymmetric effect in Amman stock exchange. They examined the stock return behavior in ASE, market efficiency, the time varying risk-return relationship, the persistence of the stock volatility and the leverage effect for the holding period 1990-2000, they found that the univariate statistics show negative skewness excess kurtosis and deviation from normality for ASE index, significance positive relationship between equity return and risk in ASE which consistent with portfolio theory.

Ritab, et al (2007) investigated the behavior of daily stock return volatility around the price limit hit for a sample of 159,189 securities listed in Amman Stock Exchange (ASE), over the years 1994, 1995 respectively. Their results indicated that stocks hit experiences their highest level of volatility on the day when stocks-hit reach their upper daily price limits of $5 \%$, and decreases significantly one day after the hit. The main features of this study are the utilization of the ARIMA model and unit root tests to distinguish the stationary of the time series for the volatility ASE. Also, we choose ASE because there are few numbers of studies that search and concern about weekly forecasting volatility data by using ARIMA model on the ASE as an emerging market, we studied in details the insurance sector, and that the data needed are available on the website of ASE. 


\section{2- Problem of the Study:}

Volatility has been one of the most active and successful areas of research in time series econometrics and economic forecasting in recent decades. Financial market volatility is a central issue to the theory and practice of asset pricing, asset allocation and risk management.

The main problem of this study is to answer about the following questions:

a- The purpose of this study is to model and quantify volatility of returns on Amman Stock Exchange using Box-Jenkins model.

b- To check the stationarity for Amman Stock Exchange for the Insurance sector using augmented Dickey- Fuller test at level or at first difference.

c- We can effectively forecasting volatility and identify a convenient technique to achieve this goal.

\section{3- Materials and Methods:}

\section{3-1- Volatility:}

There are four sources of volatility differences; asset concentration, stock market development/economic integration, microstructure effects and macroeconomic influence, and political risk (Harvey \& Bekaret, 1997). The most noticeable source is the first one that it depends on the degree of diversification and concentration natural in the IFC (International Finance Corporation) index for each country. As an economy becomes more developed, it often becomes more diverse and as a result the cross sectional volatility of the country's component stock returns should increase. That is, as stocks are less dependent on one sector, their covariance's should decrease which should increase the cross sectional variance. At the level of the index, this effect should decrease market volatility. This negative relation will not necessarily hold in more developed markets. The third is microstructure research; here we say that it is well known that the heterogeneity of trader's information sets as well as liquidity affects the variance of returns. In developed markets, large changes in prices across securities suggest a greater flow of private information being revealed to the market. Ross (1989) found the volatility of price is directly linked to the rate of information flow in the market. Schwert (1989a and 1989b) showed that macro economy is one of the underlying forces effecting stock market volatility, unfortunately, the macroeconomic data are sparse or nonexistent in some of emerging markets. For example inflation variability is an obvious candidate for an explanatory variable. The volatility trader has a different perception on the market than the habitual stock market investor. The volatility trader understands that times of declining stock prices and increasing volatility are predictable. However, periods of high volatility offer an equal number of trading opportunities as when stock prices are increasing. Therefore, volatility is not a negative. There are ways to profit regardless of market trend, and volatility is not a vengeance.

Volatility is a fact of life when investing; it can be high as well as high. However, there are ways to generate profits using many strategies. When the economy is in the low-volatility state, the standard deviation of returns is small and determining whether the economy has switched to the high-volatility state is easy .Large returns are unlikely to occur in the low volatility state, so their occurrence quickly reveals to investors that the economy is in the high-volatility state. However, the inference problem is more difficult when the economy is in 
the high-volatility state. In the high-volatility state, small returns do not immediately reveal that the economy has switched states because a reasonable chance of getting a small return exists even though the standard deviation of returns is high. A financial time series exhibits two essential properties: nonstationary and time varying volatility. Indeed, nonstationary means that a variable has no clear tendency to return to a constant value or linear trend. The second central property of a financial time series is that its volatility varies over time. The value of financial instruments depends on the expected volatility of returns. Volatility is analogous to risk: financial institutions undertake volatility assessments as part of their risk analysis exercise. Volatility can be defined as:

$$
r_{t}=\left|\log \left(x_{t}\right)-\log \left(x_{t-1}\right)\right|
$$

Where: $r_{t}$ is the returns, $x_{t}$ is the observation at time $t, x_{t-1}$ is the observation time $t-1, \log$ is the logarithm and |.| is the absolute value.

\section{3-2- Box-Jenkins Model:}

There are many forecasting techniques that used in statistics (Random Walk Model, Historical Mean Model, Moving Average Model, Weighted Moving Average Model, Exponential Smoothing Model, Regression Model, Autoregressive Conditional Heteroskedastic model (ARCH (1) Model), Exponential Generalized Autoregressive conditional heteroskedasticity model ( EGARCH $(1,1)$ Model), ARIMA Model). In this study, ARIMA model was used since (Pankratz, 1983) Box-Jenkins method produced the best forecast for $74 \%$ of the series that he evaluated, The UBJ approach has three advantages over many other traditional single-series methods. First, the concepts associated with UBJ models are derived from a solid foundation of classical probability theory and mathematical statistics. Many other historically popular univariate methods (though not all) are derived in an intuitive way. Second, ARIMA models are a family of models, not just a single model. Box and Jenkins have developed an approach that guides the analyst in choosing one or more appropriate models out of this larger family of models. The third, it can be shown that an appropriate ARIMA model produces optimal univariate forecasts. That is, no other standard single-series model can give forecasts with a smaller mean-squared forecast error (i.e., forecast error variance). Box and Jenkins propose a practical three-stage procedure for finding a good model. The three-stage are: Identification, we use two graphical devices to measure the correlation between the observations within a single data series. These devices are called an estimated autocorrelation function (abbreviated ACF) and an estimated partial autocorrelation function (abbreviated PACF). The estimated ACF and PACF measure the statistical relationships within a data series in a somewhat crude (statistically inefficient) way. Nevertheless, they are helpful in giving us a feel for the patterns in the available data. Diagnostic checking, Box and Jenkins suggest some diagnostic checks to help determine if an estimated model is statistically adequate. A model that fails these diagnostic tests is rejected. Furthermore, the results at this stage may also indicate how a model could be improved. This leads us back to the identification stage. We repeat the cycle of identification, estimation, and diagnostic checking until we find a good final model. We find a satisfactory model then we may use it to forecast. The iterative nature of the three-stage UBJ modeling procedure is important. The estimation and diagnostic-checking stages provide warning signals telling us when, and how, a model should be reformulated. We continue to re-identify, re-estimate, and re-check until we find a model that is satisfactory according to several criteria. This iterative application of the three stages does not guarantee that we will finally 
arrive at the best possible ARIMA model, but it stacks the cards in our favor. Box-Jenkins method produced the best forecast for $74 \%$ of the series that they evaluated (Pankratz, 1983). The Box - Jenkins technique is a practice for accomplishing the model past values of the time series variable and past values of the error terms. The Box - Jenkins approach consists of extracting the predictable from the observed data through a series of iterations. The most common ARIMA model included three parameters: $\mathrm{p}, \mathrm{d}$, and $\mathrm{q}$ where $\mathrm{p}$ is the number of autoregressive parameters, $\mathrm{d}$ is the number of differencing parameters and $\mathrm{q}$ is the number of moving average parameters. A general ARIMA model is in the form (Bruce et al, 2005; and John and David, 2003):

Where:

$$
z_{t}=C+\varphi_{1} z_{t-1}+\varphi_{2} z_{t-2}+\ldots+\varphi_{p} z_{t-p}+a_{t}-\theta_{1} a_{t-1}-\theta_{2} a_{t-2}-\ldots-\theta_{p} a_{t-q}
$$

$t$ : is the periodic time, $z_{t}$ : is the numerical value of an observation, $\varphi_{i}$ : for $i=1,2, \ldots, p$ are the autoregressive parameters, $\theta_{j}$ :for $j=1,2, \ldots, q$ are the moving average parameters, $a_{t}$ :is the shock element at time $t$.

To estimate the parameters $\varphi_{i}$ and $\theta_{j}$ for a fixed $\mathrm{p}$ and $\mathrm{q}$, we perform the linear multiple regression:

$$
\hat{z_{t}}=\mu+\varphi_{1} z_{t-1}+\varphi_{2} z_{t-2}+\ldots+\varphi_{p} z_{t-p t}-\theta_{1} a_{t-1}-\theta_{2} a_{t-2}-\ldots-\theta_{p} a_{t-q}
$$

There are two phases to the identification of an appropriate Box - Jenkins model: changing the data if necessary into a stationary time series and determining the tentative model by observing the behavior of the autocorrelation and partial autocorrelation function. A stationary time series is that it does not contain trend, that is, it fluctuates around a constant mean. One of the methods of transformation is by taking logarithm; it will transform the series into a stationary time series. We can write the differencing by the operator of differencing as the following $B z_{t}=z_{t-1}$. After transformation, it is clear that the observations fluctuate around the constant mean. Box and Jenkins suggest the number of Lag to be no more than $n / 4$ autocorrelations; the autocorrelation coefficient measures the correlation between a set of observations and a lagged set of observation in a time series. The autocorrelation between $z_{t}$ and $z_{t+k}$ measures the correlation between the pairs $\left(z_{1}, z_{1+k}\right),\left(z_{2}, z_{2+k}\right), \ldots$, $\left(z_{n}, z_{n+k}\right)$. The sample autocorrelation coefficients $r_{k}$ is an estimate of $\rho_{k}$ where

$$
r_{k}=\frac{\sum\left(z_{t}-\bar{z}\right)\left(z_{t+k}-\bar{z}\right)}{\sum\left(z_{t}-\bar{z}\right)^{2}}
$$

Where $z_{t}$ : The data from the stationary time series. $z_{t+k}$ : The data from k time period ahead of $t . \bar{z}:$ The mean of the stationary time series.

The estimated partial autocorrelation function PACF is used as a guide, along with the estimated autocorrelation function ACF, in choosing one or more ARIMA models that might fit the available data. The idea of partial autocorrelation analysis is that we want to measure how $\hat{z}_{t}$ and $\hat{z}_{t+k}$ are related. The equation that gives a good estimate of the partial autocorrelation is: 


$$
\hat{\varphi}_{k k}=\frac{r_{k}-\sum_{j=1}^{k-1} \hat{\varphi}_{k-1, j} r_{k-j}}{1-\sum_{j=1}^{k-1} \hat{\varphi}_{k-1, j} r_{j}} \quad k=2,3, \ldots
$$

Where $\hat{\varphi}_{k j}=\hat{\varphi}_{k-1, j}-\hat{\varphi}_{k k} \hat{\varphi}_{k-1, k-j} \quad$ and $k=3,4, \ldots ; j=1,2, \ldots, k-1$.

The stationary assumption simplifies the theory underlying UBJ models and helps ensure getting a useful estimate of parameters from a moderate number of observations, the mean of a stationary series indicates that the overall level of the series. If a time series is stationary then the mean of any major subset of the series does not differ significantly from the mean of any other major subset of the series. Also if a data series is stationary then the variance of any major subset of the series will differ from the variance of any other major subset only by chance. However, most nonstationary series that arise in practice can be transformed into stationary series through relatively simple operations.

\section{4- Results and Discussion:}

There are many tests used to prepare the Insurance sector for ASE using ARIMA model. In the beginning, the volatilities for Insurance sector were calculated by using Equation (1). Table 1 showed the Descriptive Statistics for insurance sector. Moreover, unit root test is used to test the stationarity for this sector. Finally, the autocorrelation and partial autocorrelation were achieved for Insurance sector by checking the correlation between the index lags, they used to choose the convenient tentative models.

\section{4-1- Descriptive Statistics of the Insurance Sector:}

The first phase of this analysis is based on the descriptive statistics of the Insurance sector Table 1 showed the descriptive statistics for Insurance sector. While, Figure 1 showed the original values of the insurance sector and Figure 2 showed the plot of the volatilities for the insurance sector.

Table (1)

Summary Descriptive Statistics for Insurance Sector of ASE

\begin{tabular}{l|c|c}
\hline \hline \multicolumn{3}{c}{ Descriptive Statistics for the Insurance Sector } \\
\hline \hline Estimators & Raw Insurance & Volatility Insurance \\
\hline Mean & 5096.2 & 0.010264 \\
\hline Median & 4664.1 & 0.007330 \\
\hline Maximum & 8504.4 & 0.067905 \\
\hline Minimum & 3732.4 & 0.000106 \\
\hline Std. Dev. & 1143.8 & 0.010074 \\
\hline Skewness & 1.3 & 2.22 \\
\hline Kurtosis & 0.51 & 7.26 \\
\hline Variance & 1308312.2 & 0.000101 \\
\hline SE mean & 69.2 & 0.000611 \\
\hline Total count & 273 & 272 \\
\hline \hline
\end{tabular}




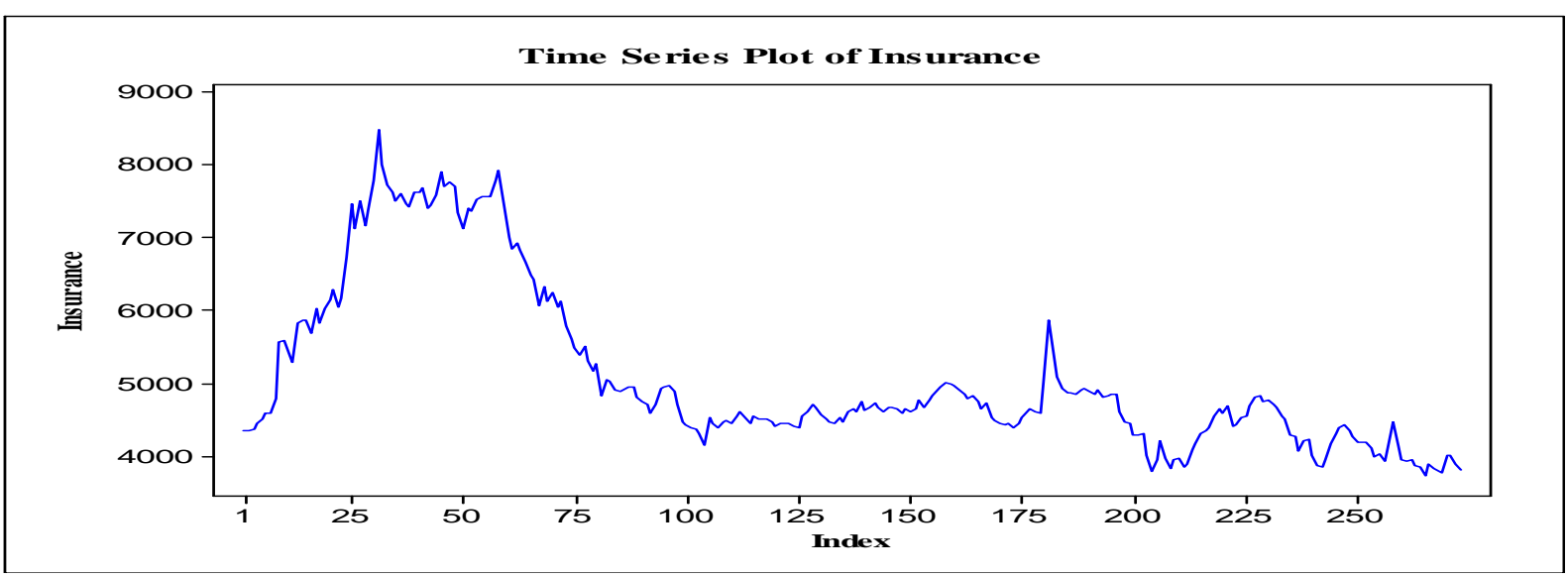

Figure 1- Original Time Series Plot of the Insurance Sector

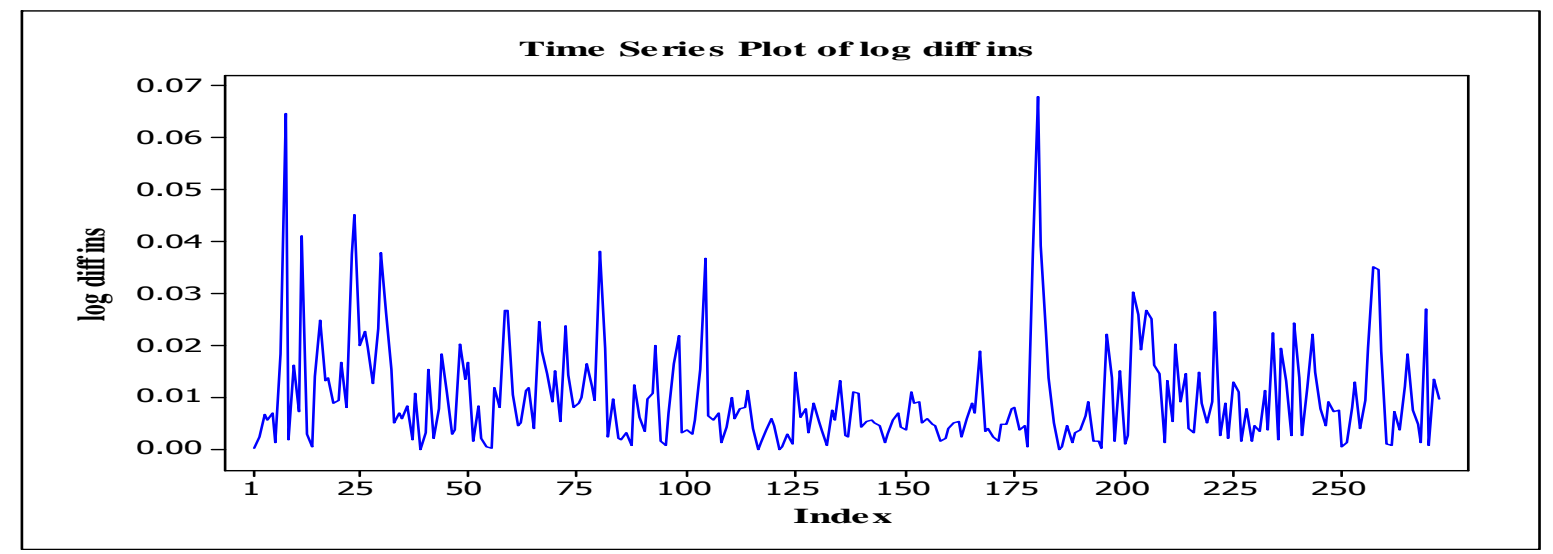

Figure 2- Plot of the volatility for Insurance Sector

\section{4-2- Unit Root Test:}

A unit root test determine whether a time series variable is non-stationary using an autoregressive model. One of the most famous tests is the augmented Dickey- Fuller test. This test used the existence of a unit root as the null hypothesis. It appears to be necessary to check the stationary in levels or at differences because there is a critical problem associated with non-stationary variables that are the spurious correlation. The more negative ADF is the stronger the rejection of the hypothesis that there is a unit roots at some level of confidence. The non-stationary time series could produce a weak result. In order to avoid the spurious correlation problem it is essential to test for unit root of the insurance sector for ASE. In this study, the Augmented Dicky-Fuller (ADF) test is proposed to examine the stationarity (unit root) of the stock market index Insurance. Tables 2 showed the ADF test for stock market indices for Insurance sector at levels 1\%,5\% and 10\%. The results of this work out, strongly confirm at the standard 5\% significance level that the stock index series are stationary in levels for insurance, so that no need to use any transformation on it. 
Table (2)

Unit Root Test (Stationary Test) of Variable (Insurance) at Levels 1\%, 5\% and $10 \%$

\begin{tabular}{|c|c|c|c|c|}
\hline ADF Test Statistic & -6.579841 & \multicolumn{2}{|c|}{$1 \%$ Critical Value* } & -3.9958 \\
\hline$\overline{\text { Level }}$ & & \multicolumn{2}{|c|}{ 5\% Critical Value } & -3.4280 \\
\hline Stationary & & \multicolumn{2}{|c|}{$10 \%$ Critical Value } & -3.1371 \\
\hline \multicolumn{5}{|c|}{ *MacKinnon Critical Values for Rejection of Hypothesis of a Unit Root. } \\
\hline & & & & \\
\hline \multicolumn{5}{|c|}{ Augmented Dickey-Fuller Test Equation } \\
\hline \multicolumn{5}{|c|}{ Dependent Variable: D(INSURANCE) } \\
\hline \multirow{2}{*}{\multicolumn{5}{|c|}{ Method: Least Squares }} \\
\hline & \multicolumn{4}{|c|}{ Included Observations: 267 After Adjusting Endpoints } \\
\hline Variable & Coefficient & Std. Error & t-Statistic & Prob. \\
\hline INSURANS(-1) & -0.638909 & 0.097101 & -6.579841 & 0.0000 \\
\hline $\mathrm{D}($ INSURANS(-1)) & -0.003657 & 0.092856 & -0.039381 & 0.9686 \\
\hline $\mathrm{D}($ INSURANS(-2)) & 0.001676 & 0.083331 & 0.020112 & 0.9840 \\
\hline D(INSURANS(-3)) & -0.029546 & 0.073462 & -0.402195 & 0.6879 \\
\hline D(INSURANS(-4)) & 0.054794 & 0.062734 & 0.873447 & 0.3832 \\
\hline $\mathrm{C}$ & 0.007854 & 0.001672 & 4.698712 & 0.0000 \\
\hline @TREND(1/01/2005) & $-8.86 \mathrm{E}-06$ & 7.64E-06 & -1.159714 & 0.2472 \\
\hline R-squared & 0.327421 & \multicolumn{2}{|c|}{ Mean Dependent Var } & $9.53 \mathrm{E}-06$ \\
\hline Adjusted R-squared & 0.311900 & \multicolumn{2}{|c|}{ S.D. Dependent Var } & 0.011444 \\
\hline S.E. of Regression & 0.009493 & \multicolumn{2}{|c|}{ Akaike Info Criterion } & -6.450701 \\
\hline Sum Squared Reside & 0.023429 & \multicolumn{2}{|c|}{ Schwarz Criterion } & -6.356654 \\
\hline Log Likelihood & 868.1686 & \multicolumn{2}{|c|}{ F-statistic } & 21.09531 \\
\hline Durbin-Watson Stat & 1.996473 & \multicolumn{2}{|c|}{ Prob (F-statistic) } & 0.000000 \\
\hline
\end{tabular}

\section{4-3- Autocorrelation and Partial Autocorrelation:}

The autocorrelation function (ACF) is the plot of autocorrelations and is very useful when examining also stationarity and when selecting from among various nonstationary models. Autocorrelation is one of the major tools in time series modeling (as guidance in choosing terms to include in an ARIMA model). The partial autocorrelation function (PACF) is the plot of partial autocorrelations, and it is also one of the major tools in time series modeling (as guidance in choosing terms to include in an ARIMA model). Figure 3 showed the ACF for the indices of insurance volatility data shows a large positive significant spike at lag 1 (this means that the autocorrelation of the successive pairs of observations within 1 time period is not within sampling error of zero). All of the other autocorrelations (for lags 2 to 15) are within the 95\% confidence limits. While, Figure 4 showed the PACF for the insurance volatility data shows a large positive significant spike at lag 1 (this means that the partial autocorrelation of the successive pairs of observations within 1 time period is not within sampling error of zero). All the other partial autocorrelations (for lags 2 to 15 ) are within the $95 \%$ confidence limits. 


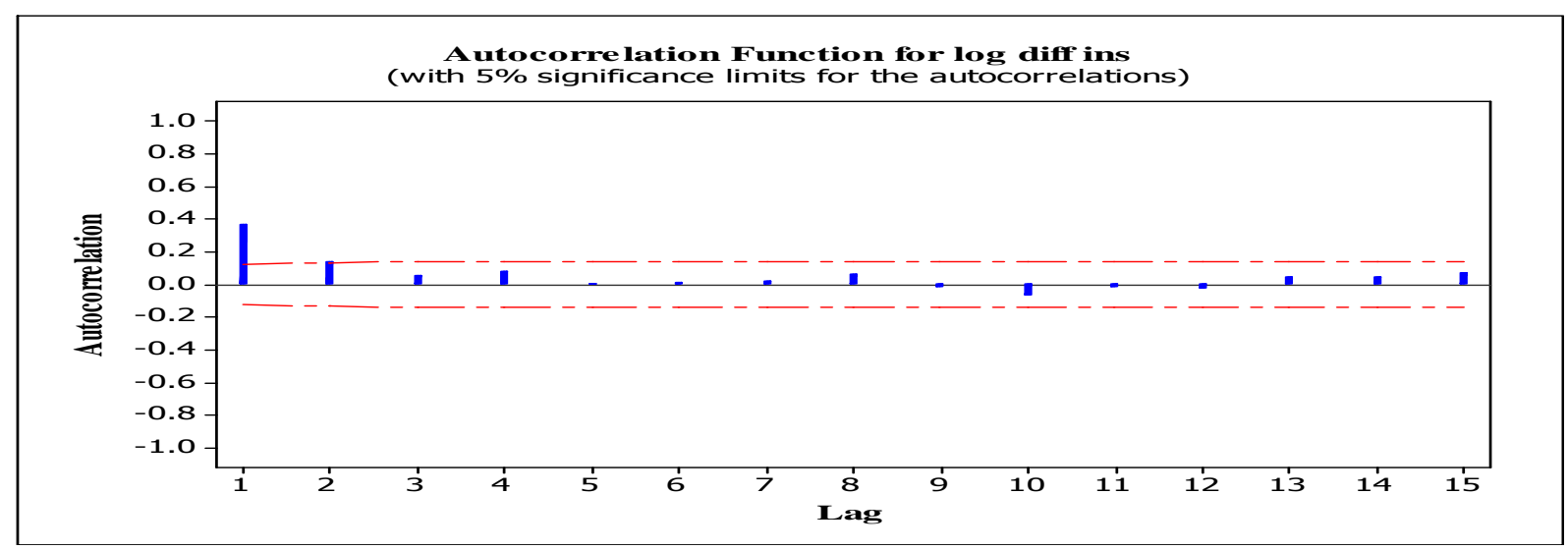

Figure 3- Autocorrelation Function for Insurance Volatility

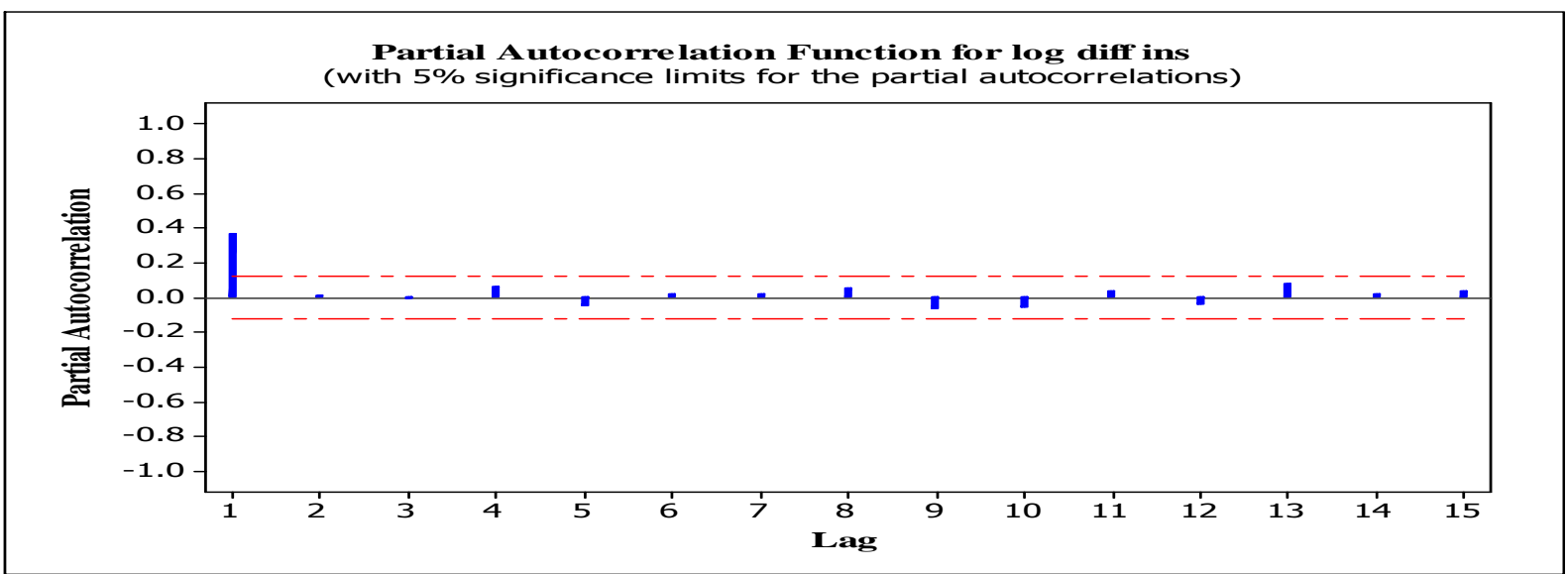

Figure 4- Partial Autocorrelation Function for Insurance Volatility

\section{4-4- ARIMA Model Analysis:}

ARIMA models are the most general class of models for a short time series forecasting. These series must be stationary, if not; it must be transformed into stationary time series, this transformation can be done by taking the difference or taking the log. In fact, the easiest way to think of ARIMA models is as fine-tuned versions of random-walk and random-trend models: the fine-tuning consists of adding lags of the differenced series and/or lags of the forecast errors to the prediction equation, as needed to remove any last traces of autocorrelation from the forecast errors. The main objective of UBJ analysis is to find a good representation of the process generating mechanism that has produced a given realization for ASE sectors, in order to build an appropriate ARIMA models for all the sectors used in this study. This representation is called a model. An ARIMA model is an algebraic statement chosen in light of the available realization. To achieve this goal we have used Equation 3.2 which contained three parameters $p, d$, and $q$ where $p$ is the number of autoregressive parameters, $\mathrm{d}$ is the number of differencing parameters and $\mathrm{q}$ is the number of moving average parameters. The most important general characteristics of theoretical AR and MA based on the construction of ACF's and PACF's are defined as follow; Stationary autoregressive (AR) processes have theoretical ACF's that decay or 
damp out" toward zero. But, they have theoretical PACF's that cut off sharply to zero after few spikes. The lag length of the last PACF spike equals the AR order (p) of the process. Moving-average (MA) processes have theoretical ACF's that cut off to zero after a certain number of spikes. The lag length of the last ACF spike equals the MA order (4) of the process. Their theoretical PACF's decay or "die out" toward to zero. Mean square error is simply the average of the squared errors for all forecasts. Also, it can be defined as a measure of accuracy of the fitted model. The MSE is not very informative by itself, but it can be used to compare fits of different ARIMA models to choose which one do better. It can be defined as:

$$
M S E=\frac{\sum_{t=1}^{n}\left(e_{t}\right)^{2}}{n}=\frac{\sum_{t=1}^{n}\left(y_{t}-\hat{y}_{t}\right)^{2}}{n}
$$

Associated with the point estimate of each parameter in Box-Jenkins model is its standard error and t-value. Let $\theta$ denote any particular parameter in a Box-Jenkins model, let $\theta^{\prime}$ denote the point estimate of $\theta$, let $S_{\theta^{\prime}}$ denote the standard error of the point estimate $\theta^{\prime}$. Then the t-value associated with $\theta^{\prime}$ is calculated by the equation

$$
t=\frac{\theta^{\prime}}{S_{\theta^{\prime}}}
$$

If the absolute value of $\mathrm{t}$ is large, then $\theta^{\prime}$ is large. This implies that $\theta$ does not equal zero, and thus that we should reject $\mathrm{H}_{0}$ : $\theta=0$, which implies that we should include the parameter $\theta$ in the Box-Jenkins model. Additionally, p-value defined to be tested regarding to the value of $\alpha$ which is the level of significant. In this study, the value of $\alpha$ is assumed to be 0.05 , since most financial studies used this value. If we reject $H_{0}: \theta=0$ in favor of $H_{a}: \theta \neq 0$, by setting $\alpha=0.05$, then we have concluded that $\theta$ is important in the model by using a test that allows only a 0.05 probability of concluding that $\theta$ is important when it is not. That is usually regarded as strong evidence that $\theta$ is important. Table 3 showed the all varieties of ARIMA models choices between the model $(0,0,0)$ to $(2,2,2)$ for the Insurance volatility sector. The best model for Insurance sector is ARIMA $(1,0,0)$, since this model gives the minimum mean square error which is 0.0000882 , then ARIMA $(1,0,2)$. Therefore, the general formula for the ARIMA $(1,0,0)$ is defined as follows:

$$
Z_{t}=\mu+\varphi_{1} Z_{t-1}+a_{t}
$$

Moreover, Table 4 showed the final estimate of the parameters for the insurance volatility sector data, the t-value for the coefficient AR (1) and for the constant are significant, based on the $t$-value and $\mathrm{p}$-value. For all t-values, they are greater than 2 , while, p-values, they are 0.000 for both coefficient of AR (1) and the constant term. 
Table (3)

The result of the best ARIMA model for Insurance volatility

\begin{tabular}{l|c|c|c}
\hline \hline Model (ARIMA) & MSE & Model (ARIMA) & MSE \\
\hline \hline$(1,0,0)$ & 0.0000882 & $(1,2,0)$ & 0.000227 \\
\hline$(1,0,1)$ & 0.0000992 & $(1,2,1)$ & Not fitted* \\
\hline$(1,0,2)$ & 0.0000889 & $(1,2,2)$ & Not fitted* \\
\hline$(1,1,0)$ & 0.0001159 & $(2,0,0)$ & 0.0000886 \\
\hline$(1,1,1)$ & Not fitted* & $(2,0,1)$ & Not fitted* \\
\hline$(1,1,2)$ & Not fitted* & $(2,0,2)$ & 0.0000889 \\
\hline$(2,1,0)$ & 0.0001099 & $(2,2,0)$ & 0.0001920 \\
\hline$(2,1,1)$ & 0.0000911 & $(2,2,1)$ & Not fitted* \\
\hline$(2,1,2)$ & 0.0000893 & $(2,2,2)$ & Not fitted* \\
\hline \hline
\end{tabular}

* The data not available to fit the model

Table (4)

Final Estimate of Parameters of the Insurance Volatility for ASE

\begin{tabular}{l|c|c|c|c}
\hline \hline \multicolumn{5}{c}{ Final Estimates of Parameters } \\
\hline \hline Type & Coef & SE Coef & T & P \\
\hline AR 1 & 0.3657000 & 0.0566000 & 06.46 & 0.000 \\
\hline Constant & 0.0064972 & 0.0005696 & 11.41 & 0.000 \\
\hline Mean & 0.0102426 & 0.0008979 & & \\
\hline \hline
\end{tabular}

Based on the Table 3 the ARIMA $(1,0,0)$ model can be derived. In order to check the adequacy of a Box-Jenkins model is to analyze the residuals $\left(Y_{t}-\hat{Y_{t}}\right)$. Figures 5 and 6 showed the residuals of ACF and PACF respectively for the volatility Insurance sector. The residuals $\mathrm{ACF}$ and PACF for volatility Insurance sector are indicated significant. Thus, the residuals are random and the model is a good fit to the data. Besides, the spikes are surrounded by the confidence limits.

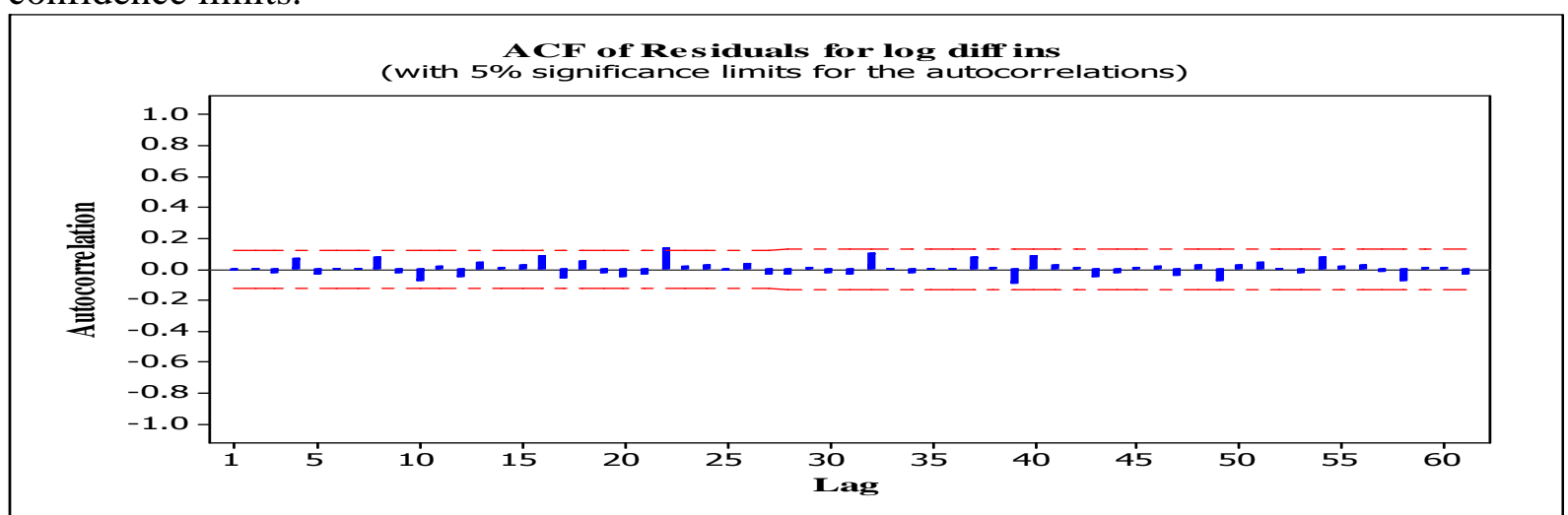

Figure 5- Autocorrelation of Residuals: Insurance Volatility Sector 


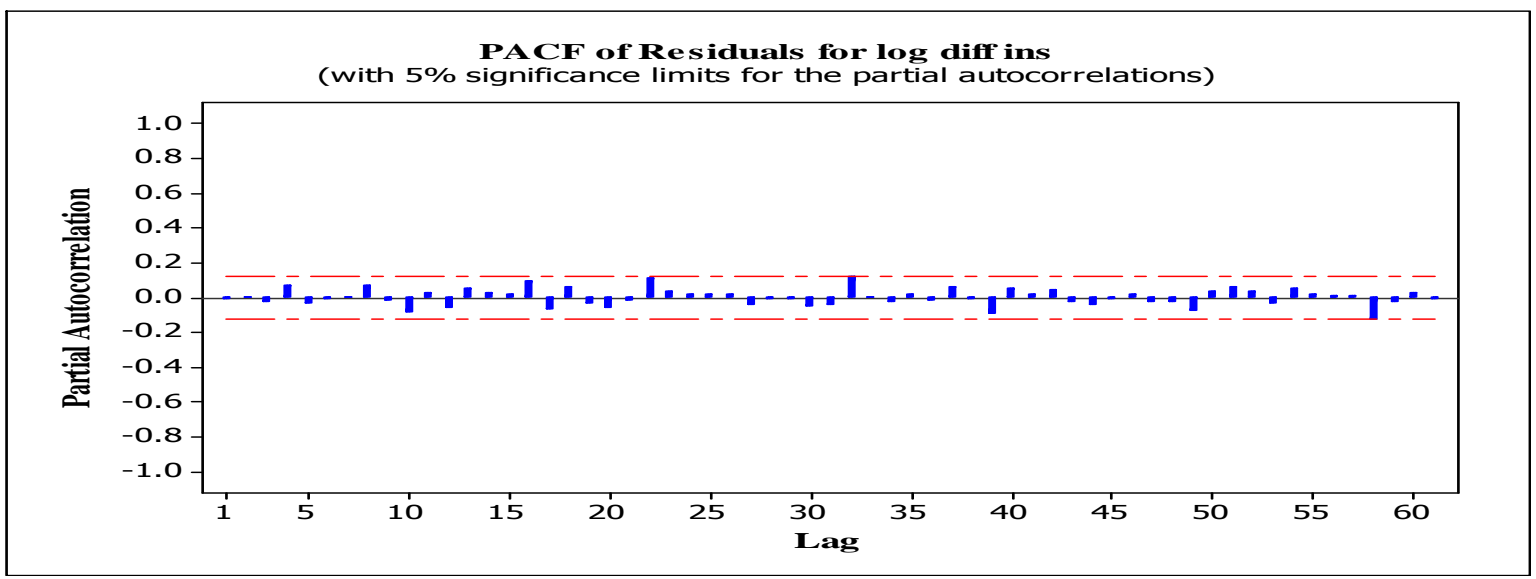

Figure 6- Partial Autocorrelation of Residuals: Insurance Volatility

The four-in-one residual plot is showed in Figure 7. The normal probability plot indicated the residuals are normally distributed. Moreover, the fit regression line showed the residuals are closed to the straight line. The histogram indicated approximately the whole data centered on the mean of data. The residuals versus fitted values indicated the variance is approximately constant. The last graph showed the residuals versus order observations which is weekly for Banks volatility sector, it is clear the whole residuals centered on and near to the $\mathrm{x}$ - axis.

At forecasting stage, the fitted model has been selected; it can be used to produce forecasts for future time periods for the Insurance volatility sector. The final model for the volatility Insurance sector is demonstrated in equation 8. While, Table 5.7 showed the predicted 10 weeks ahead of the volatility insurance sector. Whereas, Figure 5.8 showed the plot of the actual and predicted values for the volatility insurance sector, the $95 \%$ percent prediction interval for the forecasts also are computed. Since, the values of the lower interval are negative sign, we can ignore these boundaries.

The main results of the volatility forecasting are demonstrated for ASE, we studied the volatility for Insurance sector. The main results of the unit root tests are stated. In addition the ARIMA models that gave the best model to predict the 10 week ahead are tested too. Hence the best appropriate model fitted the financial- time series for insurance sectors ASE are found. The convenient model that fitted the data for the volatility insurance sector is ARIMA $(1,0,0)$ with mean equal 0065 and the coefficient was 0.366 , 


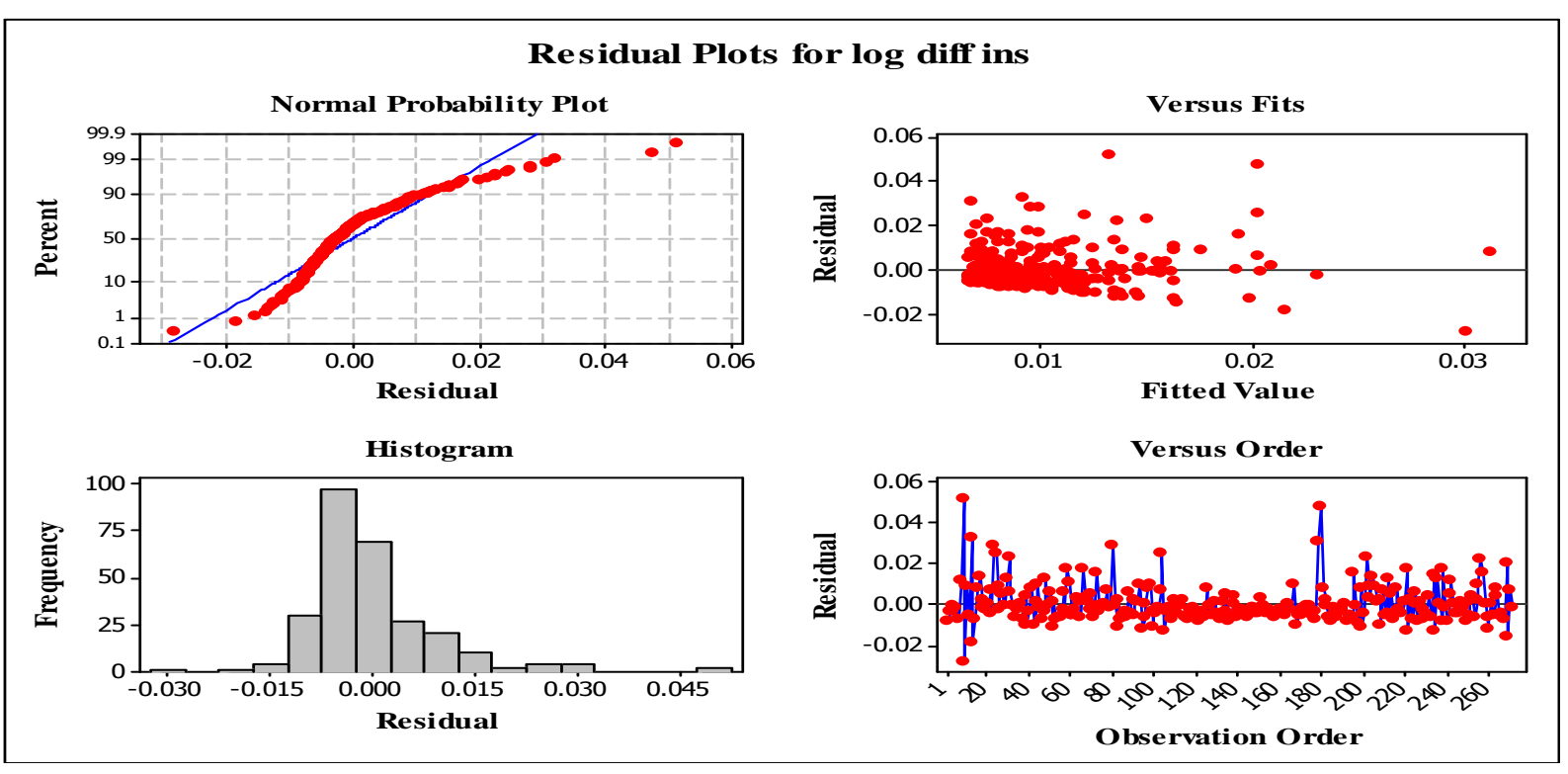

Figure 7- Residuals Plots: Insurance Volatility

Table (5)

ARIMA (1,0,0) Model: Forecasting Values for Volatility Insurance Sector

\begin{tabular}{l|c|c|c}
\hline \hline \multicolumn{5}{|c}{ Forecasts from Period 272, 95\% Limits Confidence Interval } \\
\hline Period & Forecast & Lower & Upper \\
\hline 273 & 0.0100608 & -0.0083547 & 0.0284763 \\
\hline 274 & 0.0101761 & -0.0094320 & 0.0297842 \\
\hline 275 & 0.0102183 & -0.0095439 & 0.0299804 \\
\hline 276 & 0.0102337 & -0.0095489 & 0.0300163 \\
\hline 277 & 0.0102393 & -0.0095460 & 0.0300247 \\
\hline 278 & 0.0102414 & -0.0095443 & 0.0300271 \\
\hline 279 & 0.0102421 & -0.0095436 & 0.0300279 \\
\hline 280 & 0.0102424 & -0.0095434 & 0.0300282 \\
\hline 282 & 0.0102425 & -0.0095433 & 0.0300283 \\
\hline \hline
\end{tabular}




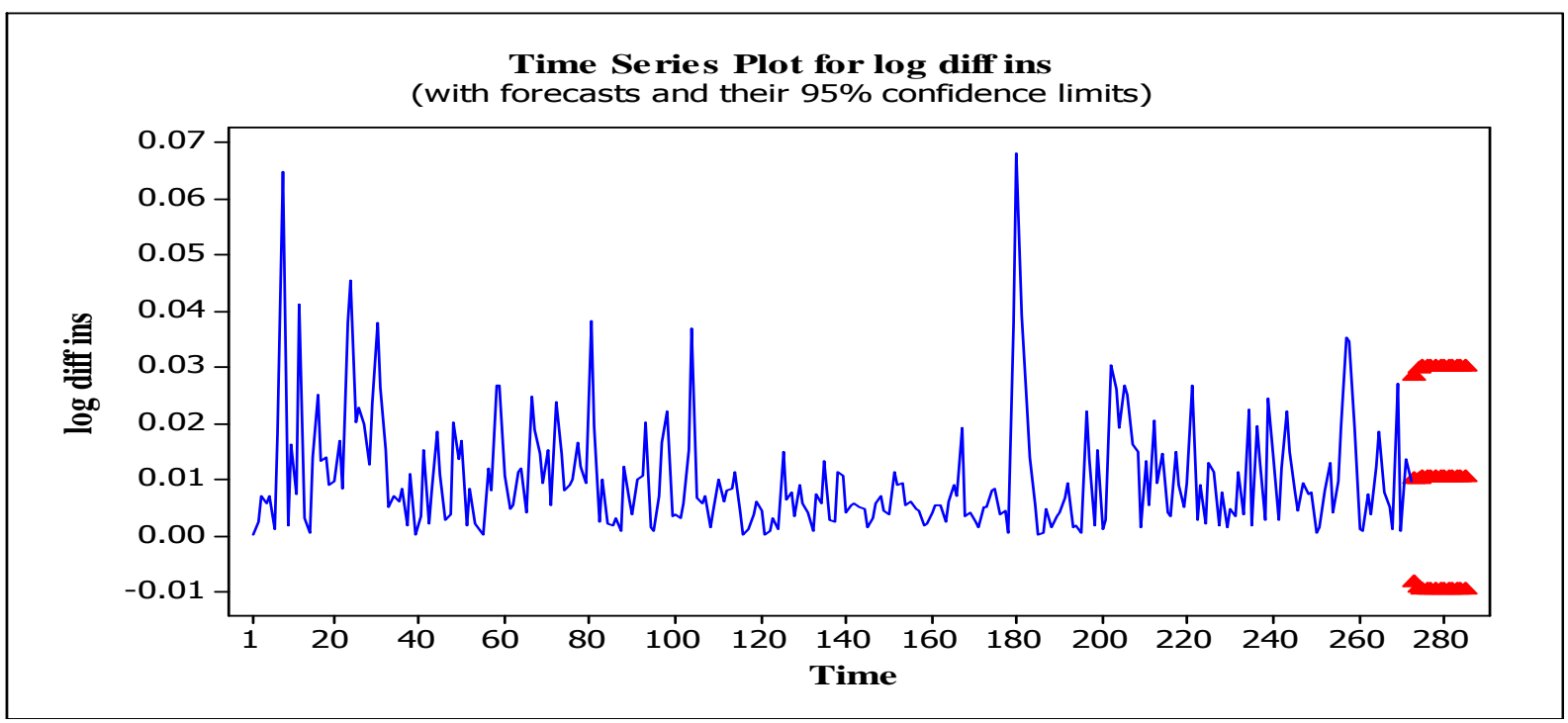

Figure 8- Actual and Forecasts Volatility Insurance for ASE

\section{4-5- Further Research:}

a- There are many forecasting methods that can be used to measure the goodness of fit for the time series of Amman Stock Exchange like GARCH models, we can use it to forecast volatility then compare its results with ARIMA models.

b- We can use another programs for example SAS to find the appreciate model for the financial time series, and then compare its results with other programs results.

c- There are many details can be illustrated in ARIMA models with more explanations. 


\section{References}

- Al-Shiab, Mohammad. (2006). "The Predictability of ASE Using the Univariate ARIMA Model", Economics Administration Science, Vol. 22, No. 2, pp.124-139.

- Al-zoubi Haitham, and Bashir. (2007). "Market Efficiency, Time Varying Volatility and the Asymmetric Effect in ASE", Managerial Finance, Vol. 33, No .7, 2007, pp.490-499.

- Bruce L. Bowerman; T. Richard O'Connell and Anne B. Koehler. (2005). Forecasting Time Series and Regression. U.S.A: Thomson Brooks/Cole.

- Chien-Chiang Lee, June-Dee Lee, Chi-Chuan Lee. (2009). "Stock Prices and the Efficient Market Hypothesis: Evidence from a Panel Stationary Test with Structural Breaks", Japan and the world Economy, Vol. 22. No.1, pp. 49-58.

- Elena Kaloty; Storis K. Staikouras. (2009). "Modeling Stock Market Volatility", In: Greg N. Gregoriou, Stock Market Volatility. New York: A Chapman \& Hall Book.

- Engle and Granger. (1987). "Co-integration and Error Correction: Representation, Estimation, and Testing", Econometrica, Vol. 55, No. 2, pp. 251-276.

- Hamao. (1990). "Correlations in Price Changes and Volatility Across International Stock Markets", The Review of Financial Studies, Vol. 3, No. 2, pp. 281-307.

- G. Bekaret and C. R. Harvey. (1997). "Emerging Equity Market Volatility", Financial Economics, Vol. 43, pp. 29-77.

- Hussein, A. Z. (2009). "A Symmetric Volatility Phenomenon: An Application to Major European Countries", International Management Review, Vol. 5, No. 1, pp. 37-49.

- Husein A. Z. (2007). "Spillover Effect and Dynamic Condition Correlation between Major European USA and Jordan Stock Markets", Unpublished Thesis, Jordan University.

- John C. B. and A. D. David. (2003). SAS for Forecasting Time Series. $2^{\text {nd }}$ Ed. Cary, NC: Institute Inc, pp. 30-193.

- Juncal Cunado, Javier, Gomez Biscarri, Fernando Perez de Gracia. (2006). "Changes in the Dynamic Behavior of Emerging Market: Revisiting the Effects of Financial Liberalization", Emerging Market Review, Vol. 17, pp. 261-278.

- Pankratz A. (1983). Forecasting with Univariate Box-Jenkins Models. New York: John Wiley \& Sons.

- Paolo Pasquariello. 92008). "The Anatomy of Financial Crises: Evidence from the Emerging ADR Market", International Economics, Vol. 76, pp. 193-207.

- Patrica E. Neor, Rickey C. kirkpatric. (1994). Introduction to Time Series Modeling and Forecasting Business Economics. McGraw-Hill.

- Poon, S. H. and C.W. J. Granger. (2003). "Forecasting Financial Market Volatility: A Review". Economic Literature, Vol. 41, No. 2, pp. 478-539.

- Reena A.; I. Carlo and L. Ricardo. (1995). Volatility in Emerging Markets. School of Business, Georgetown University, Washington, Edit Jonathan K, Financial Management Association, pp. 1-31.

- Ritab S. Al-Khouri and M. Ajlouni Moh'd. (2007). "Narrow Price Limit and Stock Price Volatility: Empirical Evidence from Amman Stock Exchange", Research, Finance and Economics, Vol. 8, pp. $163-180$.

- Yiuman,Tse. (1998). "International Transmission of Information: Evidence from the Euroyen and Eurodollar Futures Markets", International Money and Finance, Vol. 17, No. 6, pp. 909-929. 
